\title{
Inequality decomposition by factor component : a "rank-correlation" approach illustrated on the Taiwanese case
}

\author{
Martin Fournier* \\ CERDI-IDREC (Université d'Auvergne) and \\ CREST (Laboratoire de Microéconométrie)**
}

\section{Introduction}

The rise in inequality observed in most industrialised countries has led to a rising concern for distributional issues since the beginning of the 90s (Atkinson (1997); Atkinson and Bourguignon (1998); Kanbur (1999); Kanbur and Lustig (1999)). Parallel to the development of theoretical and empirical works, methodological issues have recently been raised, leading to the elaboration of new tools for the analysis of changes in the distribution of income. Inequality decomposition methods were developed in two main directions : one initiated by Juhn, Murphy and Pierce (1993) on decomposition methods based on micro-simulation techniques, the other, in the line of DiNardo, Fortin and Lemieux (1996), based on non-parametric weighting techniques. However, both methods focus on inequality decomposition by population sub-groups and offer little perspective for the decomposition of inequality by factor component ${ }^{1}$.

All the same, the question of the relative importance of various income sources in the level as well as in the distribution of total income remains a central aspect of the analysis of observed changes in income inequality.

* I would like to thank François Bourguignon, Denis Fougères, François Gardes, Sylviane GuillaumontJeanneney, Marc Gurgand and Sylvie Démurger, participants at seminars in CERDI and CREST, as well as an anonymous referee for helpful comments.

** Address : CERDI-IDREC, 65, bd François Mitterrand, 63000 Clermont-Ferrand

E-mail : M.Fournier@u-clermont1.fr, Tél. : (33) 04731775 00, Fax : (33) 0473177428

1 Developments of the micro-simulation methodology proposed in Bourguignon, Fournier and Gurgand (2001) however take into account some aspects of the question, through the explicit modelling of occupational choice behaviour and income functions in various occupations. 
Indeed, inequality decomposition by factor component allows for an evaluation of the specific impact of a given income source (capital income for example) on total income inequality. It also provides valuable information when evaluating the impact of changes in household structure on the distribution of total household income ${ }^{2}$. This feature has been at the core of various empirical studies of the rise in income inequality in the US, which point out changes in household structure as a central factor ${ }^{3}$. Usual factor decomposition of income inequality is, however, restricted to some specific inequality index and suffers from a number of drawbacks highlighted by Shorrocks' (1982) theorem.

In a recent work, Burtless (1999) uses an alternative methodology to study the impact of changes in the correlation between spouses' income on US household income distribution. This paper argues that the method succinctly and intuitively exposed by Burtless on a specific empirical framework can be systematised into a general decomposition methodology allowing one to overcome a number of drawbacks inherent to the use of standard decomposition procedures. This method, which we will call the rank-correlation method, does not rely on any parametrical assumptions and provides easily interpretable results as shown by the illustration taken from the Taiwanese case provided in the second part of this paper.

After a decrease in inequality since the beginning of the 50s, Taiwan has experienced a worsening of household income distribution since the end of the 70s. Bourguignon, Fournier and Gurgand (2001) show that an important part of the observed rise in inequality can be imputed to changes in household structure. Several other studies also point out the unequalizing effect of rising endogamy in the assortative mating of spouses in Taiwan (Fields and Leary (1997); Tsai (1994)). However, usual procedures fail to provide a specific evaluation for the magnitude of this phenomenon. The second part of this paper proposes a new evaluation of this issue through the implementation of the rank-correlation method on Taiwanese data over the 1979-94 period.

The paper is organised as follows. Section 2 discusses theoretical results concerning standard methods for inequality decomposition by factor components and proposes a systematisation of the alternative approach initiated by Burtless (1999). Section 3 applies the method to income distribution changes in Taiwan over the 1979-94 period. Section 4 concludes and discusses further methodological developments to be derived from this approach.

2 Total household income can indeed be considered as the sum of individual incomes derived by household members.

3 See tor example Burtless (1999), Gottschalk and Danziger (1993) and Lerman (1996). 


\section{A new approach to inequality decomposition by factor component}

\subsection{Standard decomposition procedures : Shorrocks' theorem}

Usual inequality decomposition by factor components can be formalised as follows. Let $Y$ be total income derived from $N$ distinct income sources :

$$
Y=\sum_{k=1}^{N} Y_{k}
$$

and let $I$ be an inequality index. Decomposing inequality by factor components consists in deriving a set of $N$ contributions such that :

a) $S_{k}$ is a function of the distribution of the $k$ th income source - written $\left\{Y_{k}\right\}-$ and of its relative share in total income $\left(\pi_{k}\right)$.

b) $I(Y)=\sum_{k=1}^{N} S_{k}\left(\left\{Y_{k}\right\}, \pi_{k}\right)$

$S_{k}$ thus represents the $k t h$ income source contribution to observed inequality in total income $Y$.

Two main approaches can be found in the literature. The first includes works based on the decomposition of the variance of income and, following Fei, Ranis and Kuo (1978), on the decomposition of the Gini coefficient. This approach tries to define easy-to-apply and intuitively appealing decompositions but remains based on ad hoc formulations. The second approach follows Shorrocks' (1982) formalisation of inequality decomposition by factor components through the definition of a set of axioms leading to a general decomposition procedure.

Shorrocks (1982) proposes a formalisation for inequality decomposition by factor component. He shows that standard decomposition procedures rely on strong ad hoc implicit hypotheses concerning the allocation of interaction effects between income sources to the contributions of each income source. Indeed, Shorrocks shows that there is an infinite number of possible decomposition rules for any given inequality index depending on the hypothesis made and emphasises the necessity to impose further decomposition constraints. Proposing a series of simple straightforward axioms, Shorrocks proves the following theorem:

Theorem : Under six relatively intuitive hypotheses concerning the decomposition rule, for any given inequality measure (I), decomposing inequality by factor component leads to:

$$
\frac{S_{k}\left(Y_{k}, Y\right)}{I(Y)}=\frac{\operatorname{Cov}\left(Y_{k}, Y\right)}{\operatorname{Var}(Y)}=s_{k}
$$


This result is extremely strong since, under Shorrocks' six hypotheses, the inequality share imputable to the $k t h$ income source $\left(s_{k}\right)$ does not depend on the choice of the inequality index. Decomposition rule (2) indeed provides, for any inequality index, a relative contribution for the $k t h$ income source equal to that obtained naturally from the decomposition of the variance.

The main drawback of the approach defined by Shorrocks (1982) is thus the independence of the relative contributions of income sources with respect to the choice of the inequality index ${ }^{4}$. This property also implies that the contribution of any income source to observed changes in inequality only depends on total income inequality (and not on the inequality measured on the marginal distribution of this specific source). Shorrocks' (1982) theorem is thus more an impossibility result than a practical framework of analysis. An impossibility due to the necessity of dealing with existing interrelations between income sources. Indeed, three dimensions are at stake in the decomposition of inequality by factor components : inequality observed within each income source, relative shares of income sources in total income, and the existing correlation between income sources. Decomposing inequality by factor components as defined above thus relies on some specific allocation procedure for the inequality (or equality) induced by the correlation between income sources. Shorrocks (1982) shows that there is an infinity of such allocation procedures and that imposing enough constraints to overcome this indetermination leads to a very restrictive decomposition framework. The only acceptable decomposition procedure is indeed restricted to the natural decomposition of one of the less attractive inequality indexes : the square of the coefficient of variation.

\subsection{An alternative approach for dynamic inequality decomposition by factor component : the rank correlation method}

We argue here that some answers to the preceding limitations of inequality decomposition by factor components can be given for dynamic decompositions (i.e. changes in income distribution) $)^{5}$. As mentioned above, the evolution of the overall distribution of total income can be considered as the combination of three factors : changes in the relative share of various sources in total income, changes in the marginal distribution of each income source, and changes in the correlation between income sources. Difficulty arises when trying to disentangle these three dimensions since there is no unique way to consider a variation of the marginal distribution of a specific income

4 This drawback led various authors to relax some of Shorrocks' axioms. See in particular Chantreuil and Trannoy (1997) and following works based on the Shapley value (Chantreuil and Trannoy (1999). Shorrocks (1999)).

5 Most empirical studies try to explain changes in income distribution or differences between income distributions, both of which can be dealt with the methodology presented here. 
source, keeping constant both the marginal distribution of other sources and the correlation between sources.

Burtless (1999), proposes an empirical study of income inequality in the US, using an alternative approach which opens new perspectives in inequality decomposition by factor components. His approach relies on a simple idea : a shift from statistical correlation to rank correlation. We argue here that this approach, presented succinctly and intuitively by Burtless on a specific case study, can be systematised and allows for the evaluation of the specific effects of changes in the marginal distribution of income sources as well as of changes in the correlation structure between sources.

This method consists in affecting to individuals (or households) observed at date $t$ a counter-factual income component keeping either marginal distributions or rank-correlation between sources unchanged. Two types of simulation can thus be computed in order to isolate the two effects.

\subsubsection{General description of the method}

Suppose that total individual ${ }^{6}$ income at any date $t$ is derived from two income sources ${ }^{7} y_{1}$ and $y_{2}$, i.e. $y=y_{1}+y_{2}$. Changes in the distribution of total income $y$ can be considered, as discussed above, as resulting from three different forces: (i) changes in the marginal distribution of $y_{1}$, (ii) changes in the marginal distribution of $y_{2}$, and (iii) changes in the correlation structure between $y_{1}$ and $y_{2}$.

Let note $y_{i}$ income $y_{i}$ observed at date $t$ and $y_{i}^{\prime}$ income $y_{i}$ observed at date $t^{\prime}$. Here we want to evaluate the specific contribution of forces (i) to (iii) in the observed evolution of the distribution of total income from $y=y_{1}+y_{2}$ to $y^{\prime}=y_{1}^{\prime}+y_{2}^{\prime}$.

A change from $\left(y_{1}, y_{2}\right)$ to $\left(y_{1}^{\prime}, y_{2}\right)$ has two distinct effects that we want to isolate : a cardinal effect (the change in the marginal distribution of $y_{1}$, i.e. force (i) above) and an ordinal effect (the change in the ranking of individuals in terms of $y_{1}$, i.e. force (iii) above). Focussing on the rankcorrelation structure leads to two simple procedures, which allow for the specific evaluation of forces (i) to (iii) above.

\subsubsection{Changes in the marginal distribution of income source $y_{i}$ : forces (i) and (ii)}

Any individual observed at date $t$ at rank $n_{1}$ in the income scale of source $y_{1}^{n 1}$, is imputed the income $y_{1}^{\prime n 1}$ of the individual corresponding to the same rank $n_{1}$ in $y_{1}$ but observed at date $t^{\prime}$. The simulation derived from this reallocation procedure keeps the distribution of other income sources observed in $t$ unchanged and provides a counter-factual marginal distribution for income source $y_{1}$ which corresponds to that observed at date $t^{\prime}$. Comparing

6 The term "individual" is to be understood here as any unit (individual, household, family, etc.).

7 The generalisation to three sources and more is straightionward. 


\begin{tabular}{|c|c|c|c|c|c|c|c|c|c|}
\hline & & Date & & & & & Date & & \\
\hline Incon & Rank & Incon & Rank & $y=$ & Incon & Rank & Incon & Rank & $y=$ \\
\hline$y_{1}$ & $r_{1}$ & $y_{2}$ & $r_{2}$ & $y_{1}+y_{2}$ & $y_{1}$ & $r_{1}$ & $y_{2}$ & $r_{2}$ & $y_{1}+y_{2}$ \\
\hline 10 & 2 & 5 & 1 & 15 & 15 & 3 & 10 & 1 & 25 \\
\hline 5 & 1 & 15 & 2 & 20 & 13 & 2 & 15 & 2 & 28 \\
\hline 25 & 3 & 30 & 3 & 55 & 12 & 1 & 25 & 3 & 37 \\
\hline
\end{tabular}

Table 1 : Distributions of income sources at dates $t$ and $t^{\prime}$

inequality measured on the counter-factual total income to observed total income inequality in $t$ thus provides the specific effect of changes in the distribution of income source $y_{1}$ keeping rank-correlation between sources unchanged. Of course, this simulation alters the statistical correlation between income sources but it preserves the rank-correlation. ${ }^{8}$

A practical question is raised when two individuals have the same rank in $y_{1}$. Two procedures are then possible: $i$ ) giving both the same counterfactual income $\bar{y}_{1}$ or, $\left.i i\right)$ randomly imputing each individual a different rank. In the first case, the marginal distribution of $\tilde{y}_{1}$ is not strictly equal to that of $y_{1}^{\prime}$. In the second case, two individuals, with the same observed income are imputed different counter-factual incomes. The second approach has been preferred in the empirical part, however, since this question only concerns a very small number of individuals; both approaches lead to very similar results. This would, however, be an important point in the case of grouped income data.

\subsubsection{Change in the rank-correlation structure: force (iii)}

Symmetrically, the rank-correlation structure of income sources observed at date $t^{\prime}$ can be applied to the population observed at date $t$ through the permutation of observed values for various income sources across individuals. Let $\pi$ (resp. $\pi^{\prime}$ ) be the function relating ranks in $y_{1}$ and $y_{2}\left(r_{1}\right.$ and $\left.r_{2}\right)$ at date $t$ (resp. $t^{\prime}$ ). In order to evaluate the specific effect of force (iii), we simply apply $\pi^{\prime}$ to the population observed at date $t$. This corresponds to a re-allocation of, say, income source $y_{1}$ between individuals observed in $t$. It thus preserves the marginal distributions $y_{1}$ and $y_{2}$, whereas the simulated rank-correlation structure between sources is that observed at date $t^{\prime 9}$.

${ }^{B}$ Counter-factual imputed incomes have to be weighted by the share of the mean of the income source at dates $t$ and $t$ ' in order to preserve the overall mean income observed in $t$.

9 Here again, the statistical correlation simulated will not a priori correspond to that of date $t^{\prime}$. 


\subsubsection{Illustration ${ }^{10}$}

Even though the preceding formulation may appear a little abstruse at first sight, the procedure is actually very simple and can be straightforwardly implemented as can be seen in the following simple example.

\begin{tabular}{cc|cc|c}
\hline Income & Rank & Income & Rank & $\tilde{y}=$ \\
$\tilde{y}_{1}$ & $\tilde{r}_{1}$ & $y_{2}$ & $r_{2}$ & $\tilde{y}_{1}+y_{2}$ \\
\hline 13 & 2 & 5 & 1 & $\mathbf{1 8}$ \\
12 & 1 & 15 & 2 & $\mathbf{2 7}$ \\
15 & 3 & 30 & 3 & $\mathbf{4 5}$ \\
\hline
\end{tabular}

Table 2 : Change in the marginal distribution of income source $y_{1}$ keeping marginal distributions of other income sources and correlation between sources unchanged (i)

\begin{tabular}{cc|cc|c}
\hline Income & Rank & Income & Rank & $\tilde{y}=$ \\
$\tilde{y}_{1}$ & $\tilde{r}_{1}$ & $y_{2}$ & $r_{2}$ & $\tilde{y}_{1}+y_{2}$ \\
\hline 25 & 3 & 5 & 1 & $\mathbf{3 0}$ \\
10 & 2 & 15 & 2 & 25 \\
5 & 1 & 30 & 3 & 35 \\
\hline
\end{tabular}

Table 3 : Change in the rank-correlation between sources keeping marginal distributions of sources unchanged (iii)

\subsubsection{Discussion}

These two simulation procedures are relatively simple to implement and are based on totally non-parametric computations since they only use the rank structure of various income sources but affect various observed incomes among individuals differently.

The method presented here cannot strictly speaking solve the question of the sharing rule for the correlation between sources pointed out by Shorrocks (1982) in terms of statistical correlation. Statistical correlation is indeed modified by simulations. However, it provides an evaluation procedure leading to easily interpretable results. Moreover, this method presents

$10 \bar{A}$ formal recapitulation is provided in the appendix. 
the major advantage of allowing for a distinction between changes in the correlation between income sources and changes in the marginal distribution of sources. Indeed, standard decomposition procedures only provide a global evaluation of the two aspects subject to some ad hoc sharing rule for the correlation effect between sources.

A second major advantage of the method is that it allows for a decomposition of the whole distribution of income since it is not based on a specific inequality index. It thus allows for the decomposition of Lorenz curves as well as any synthetic measure, every different index providing different results depending on its specific sensitivity properties.

A third interesting feature of the method comes from the fact that it does not rely on any modelisation or parametrical assumption but can easily be combined with various parameterisations in order to deal with related issues such as changes in labour force participation or changes in household size.

It should be noted that decompositions presented here from date $t$ to date $t^{\prime}$ can as well be computed symmetrically from date $t^{\prime}$ to date $t$. As for any decomposition analysis of the "shift-share" type, both paths a priori lead to different results since the overall effect of any given evolution depends on the structure upon which it is taking place ${ }^{11}$. Confronting computation results provides some "robustness" test for measured effects. Moreover, income sources can be permutated in table 2 leading to the evaluation of changes in the marginal distribution of $y_{2}{ }^{12}$.

In the same line, decomposition results do not provide an exact decomposition of inequality changes and the sum of various effects is not $a$ priori equal to total observed evolution. This is a usual feature in dynamic decompositions, which comes from the fact that the effect of a specific change depends on the original structure it affects. It would be possible to provide exact decompositions through sequential simulations, every simulation based on previous simulation results. This type of decomposition would, however, lead to an important number of possible paths, each path providing a different result. The difference between the sum of simulated effects and observed inequality changes reflects the way in which different forces tend to offset (positive residual) or magnify (negative residual) each other.

Finally, it should be stressed, as said earlier, that the approach proposed here can only provide a decomposition of changes or differences in income distribution and does not give any static decomposition at a specific point in time as standard methods do. However, the empirical use of static inequality decompositions often remains of a limited interest.

11 It is indeed clear that a rise in inequality in a specific income source increases overall inequality all the more since the income source is highly positively correlated with its complementary to total income.

12 The effect measured for the modification of the correlation between income sources is however the same, whichever income source the simulation is based upon. 


\section{Taiwan 1979-94}

This section provides an illustration of the rank-correlation method to the evolution of household income distribution in Taiwan over the 1979-94 period.

\subsection{Evolution of household income distribution in Taiwan (1979-94)}

Taiwan appears as a counter-example to the Kuznets (1955) hypothesis predicting an inverted U-shape relationship between economic development and inequality. Indeed, since the settlement of the Republic of China in Taiwan in 1949, the country has experienced an exemplary growth process, not only without increasing inequality but even with decreasing income disparities up to the beginning of the $80 \mathrm{~s}$. This evolution made Taiwan in the 90 s a newly industrialised country with high growth rates and inequality levels comparable or below western countries' standards.

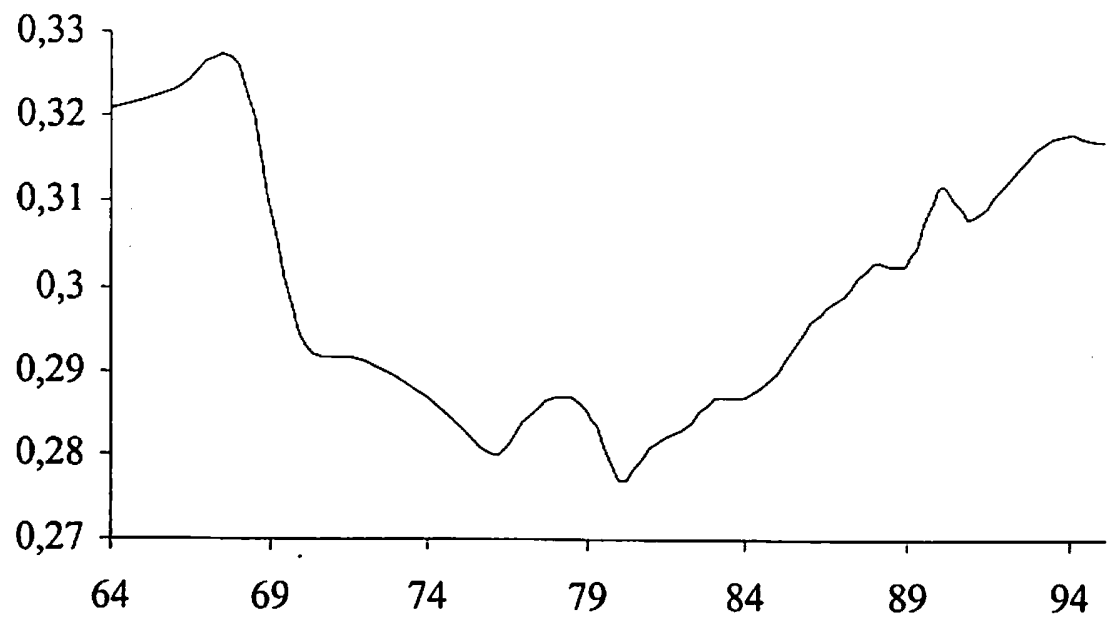

Figure 1 : Inequality of household income (1964-96)

(Gini)

As shown in figure 1, household income distribution has, however, become more unequal since the end of the $70 \mathrm{~s}$, which has lead to a series of discussions on what has been called, following Hung (1996), the "great U-turn" ${ }^{13}$.

13 This result, illustrated here on gross total household income, is statistically significant and robust to the use of various equivalence scales (Fournier (1999), pp.222-224). 
Conversely, the distribution of individual wages in Taiwan has shown a continuous decrease in inequality since the end of the 70s. The 80s and 90 s thus appear as a period of divergence between decreasing inequality at the individual level and increasing inequality in total household income. Using a micro-simulation based decomposition method, Bourguignon, Fournier and Gurgand (2001) show that these trends come from the combination of various compensating forces. Indeed, a strong unequalising force, at the individual as well as at the household level, is shown to be caused by the rise in returns to education, whereas the expansion of education in the population has had the opposite effect. This study shows that most of the observed divergence between the evolution in individual and household income inequality should imputed to changes in household structure. Other recent studies of the Taiwanese income inequality also emphasize changes in household structure as a key factor for explaining the observed rise in household income inequality since the end of the 70s (Chu (1997); Fields and Leary (1997); Schultz (1997); Tsai (1994)). Usual analyses of the decomposition of inequality changes as well as recent methodological developments cannot provide any further study of this phenomenon, however. The rank-correlation method presented above thus appears as a valuable complementary tool for the identification of the sources of income inequality changes in Taiwan.

\subsection{Data}

Fully comparable micro-data from household survey are only available for the 1979-94 period; we will thus restrict the analysis to the observed rise in household income inequality over this period.

The empirical work is based on a series of household surveys conducted annually by the Taiwanese government since 1979 on samples composed of 16, 400 households. (Directorate-General of Budget Accounting and Statistics, DGBAS). Household surveys are actually available from 1976 on, but the quality of data prior to 1979 , as well as various adjustments made on the size of the sample lead us to restrict the analysis to the period from 1979 onwards. The surveys are intended to provide information on the living standards of Taiwanese inhabitants and actually provide rich, valuable and reliable data ${ }^{14}$. A new sample is drawn every year; providing a set of repeated cross section and not a panel.

Finally, it should be noted that all income sources considered in the following empirical work are evaluated as income per adult equivalent, using the square root of the total number of household members as equivalence scale $^{15}$.

\footnotetext{
14 See Deaton and Paxson (1993) for a discussion on the reliability of the data.

15 Most results are robust to the use of various equivalence scales
} 


\subsection{Changes in the structure of household income by type of household members}

The joint evolution of household structure, participation behaviour and remuneration structure which took place in Taiwan over the period studied led to major changes in the structure of primary household income by type of household members. This evolution is illustrated in table 4.

\begin{tabular}{l|cc|cc}
\hline & \multicolumn{2}{|c|}{ Share in total income } & \multicolumn{2}{c}{ Share in wage income } \\
& 1979 & 1994 & 1979 & 1994 \\
\hline Wages & & & & \\
Household head & 49.5 & 50.1 & 69.2 & 65.7 \\
Spouses & 6.3 & 12.3 & 8.8 & 16.1 \\
Children & 8.0 & 5.1 & 11.2 & 6.7 \\
Other members & 7.7 & 8.7 & 10.8 & 11.4 \\
$\begin{array}{l}\text { Income from independent } \\
\text { activities* }\end{array}$ & 28.5 & 23.9 & - & - \\
\hline
\end{tabular}

Note : $\left(^{*}\right)$ Income derived from independent activities of household members (agricultural or not) cannot be attributed to any particular household member in the data

Table 4: Structure of primary household income by type of household members (1979-94)

First, it should be noted that the share in household wage income provided by household heads substantially declined, whereas that of spouses increased quite dramatically. Moreover, increasing enrolment at higher education levels as well as a decline in fertility led to a significant decrease of the relative share of children's income in total household income.

Changes in household structure also came from changes in the correlation between the characteristics of household members, and especially of spouses (Tsai (1994)). At the same time, changes in participation behaviour, especially for spouses and children, has also led to a modification of the correlation between individual incomes within households ${ }^{16}$.

The following empirical work proposes an implementation of the rankcorrelation method on total household income considered as the sum of individual income provided by various household members and income derived from independent activities.

16 For a detailed study of changes in female labour supply in Taiwan over the 1979-94 period, see Bourguignon, Fournier and Gurgand (1999). 


\subsubsection{Changes in the marginal distribution of individual incomes of different household members}

The first decomposition exercise proposed in the rank-correlation decomposition method described above consists in isolating the specific impact on total household income of observed changes in the distribution of a specific income source. Figures 2 to 5 represent the specific effect of changes in the marginal distribution of wage income for each type of household member. Effects are measured keeping the marginal distribution of other income sources as well as rank-correlation between the source studied and its complement to total household income unchanged. Figures show the simulated variation in Lorenz curves. A negative curve on the whole income scale corresponds to an increase in inequality induced by the simulation (i.e. dominance of Lorenz curves). Finally, as mentioned above, simulations are computed from 1979 to 1994 as well as from 1994 to 1979 and the confrontation of both results can be viewed as a robustness test.

The plain curve represents the observed change in primary household income distribution as measured by Lorenz curves. Its negative sign up to the very top of the distribution reflects the observed rise in inequality described above using Gini coefficients ${ }^{17}$.

These figures show that changes in the marginal distribution of all types of members, except heads and children, have had an equalising effect on overall household income distribution. The effect observed for household heads is ambiguous, since curves cross the horizontal axis (which corresponds to a cross in Lorenz curves). However, the curves being first above and then below the horizontal axis, the effect is equalizing at the bottom of the distribution and unequalizing at the top. The Lorenz dominance at the bottom of the distribution implies that measured effects are equalizing for inequality indexes most sensitive to changes at the bottom of the distribution. As noted above, the distribution of individual income has become more equal over the period studied, which naturally entails that the specific effect of changes in the marginal distribution of most types of household members has had an equalising effect on total household income distribution.

Results concerning children of household heads, however, call for further discussion. Indeed, the study of income distribution changes within this class also shows a decrease in inequality; figure 4, however, shows a non-ambiguous rise in inequality for total household income distribution induced by this evolution. This result comes from the rapid widening of enrolment at higher levels of education, which led children to enter the labour market much later. This evolution comes both from a strong concern and political efforts on the part of the Taiwanese government ${ }^{18}$ and from a loosening of the budget constraint for poorer households, induced by the high growth rates observed all over the period. As lower income households tend

17 Most inequality indicators show a rise in inequality. See Fournier (1999).

18 Free and compulsory education was increased from 6 to 9 years in 1968 and a law has recently been passed to implement a further increase to 12 years by 2001 . 
Figures 2 to 5 : Variation in the marginal distribution of wage income for different household members

Variation in Lorenz curves - Household primary income (1979-94)

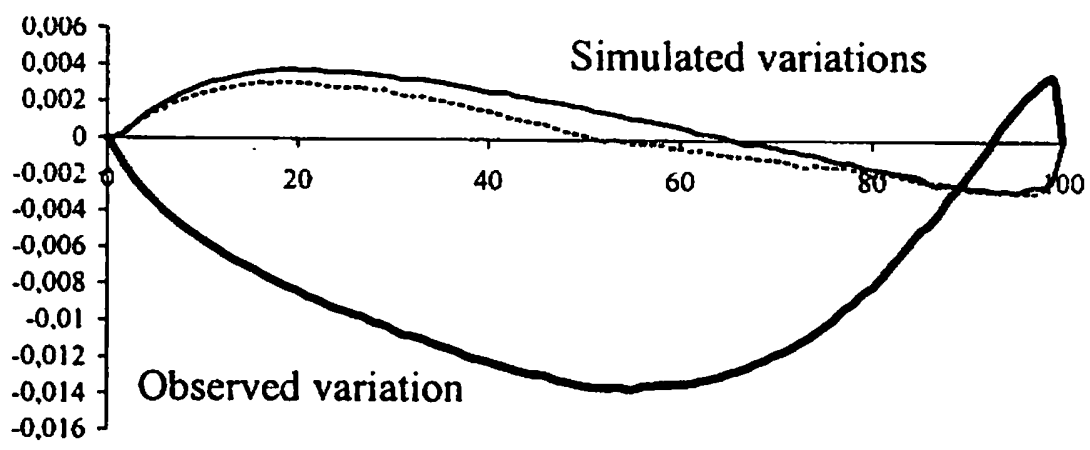

Figure 2: Household head

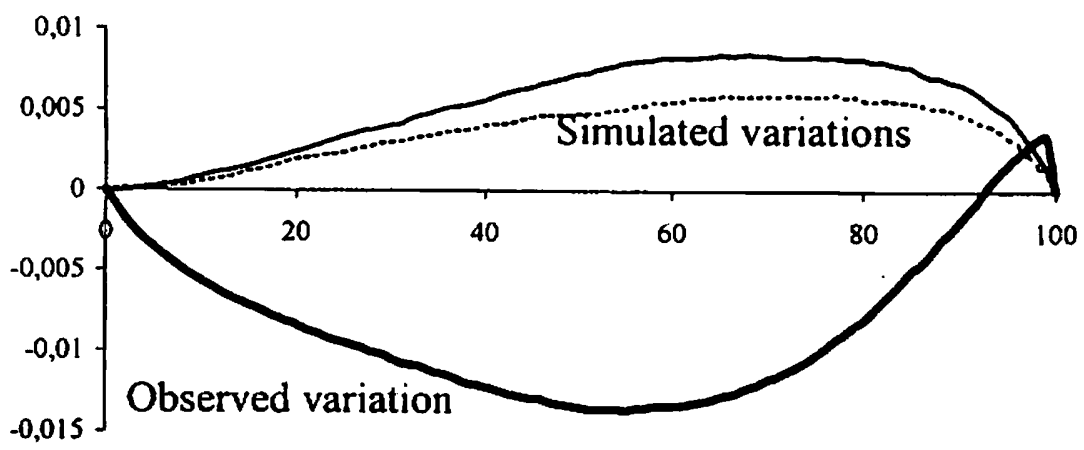

Figure 3 : Spouses

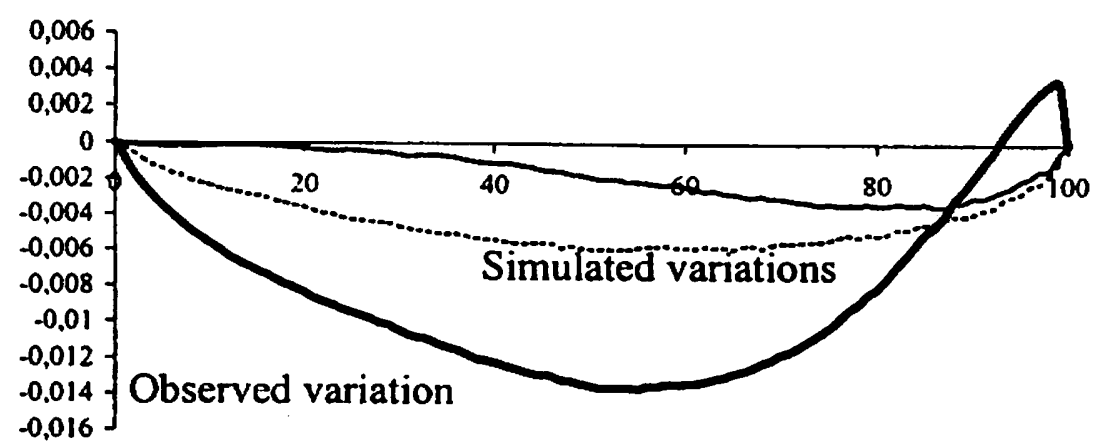

Figure 4: Children 


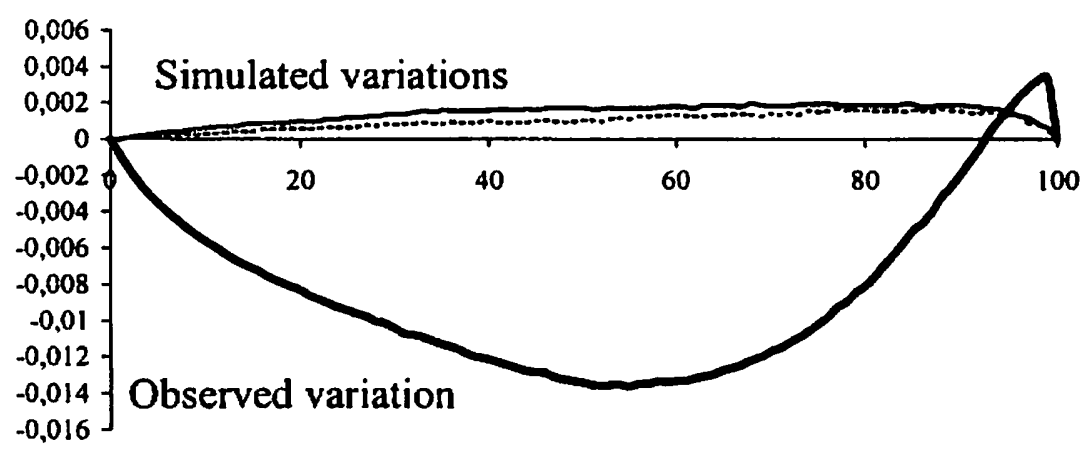

Figure 5 : Other members

Thick plain lines : observed variation.

Doted lines : simulations based on 1979 initial structure.

Light plain lines : simulations based on 1994 initial structure.

Notes: Abscises represent the cumulative share of households, ranked by increasing tolal income. The equivalence scale used is the square root of the total number of household members. The number of household members weights households.

to have more opportunities to keep their children enrolled in schools, their relative income in the whole population suffers all the more since children represent a much larger part of total household income at the bottom of the distribution of household income. Applying the observed distribution of children's income in 1994 to the population observed in 1979 thus induces a net loss coming from the increase in the share of non-working children, which is concentrated at the bottom of the distribution.

\subsubsection{Changes in the correlation between incomes of household members}

The second type of exercise proposed by the rank-decomposition method consists in measuring the specific impact of changes in the correlation between income sources, keeping marginal distribution of sources unchanged. Figures 6 to 9 show the specific impact of changes in rank-correlation between incomes of each type of household member and its complementary to total household income.

Figures 6 and 7 show non-ambiguous unequalizing effects of strong magnitude induced by changes in rank-correlation for household heads and spouses. These results can be related to two main simultaneous factors : rising female participation and rising endogamy in the assortative mating of spouses especially in relation with education and age ${ }^{19}$ (Tsai (1994), Fields and Leary (1997)). More specifically, concerning the rise in female labour supply, Bourguignon, Fournier and Gurgand (2001) show a sizeable unequa-

19 Correlation coefficients between education of spouses rose from 0.66 to 0.72 between 1979 and 1994. A rise from 0.84 to 0.90 took place over the same period concerning the age of spouses. 
Figures 6 to 9: Variation in the correlation between the income of household members and total household income

Variation in Lorenz curves - Household primary income (1979-94)

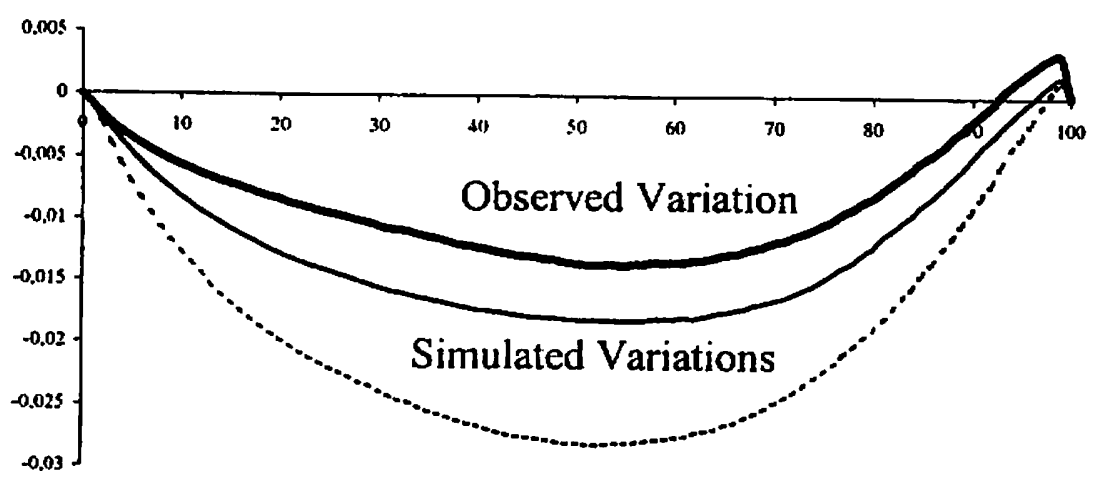

Figure 6 : Household head

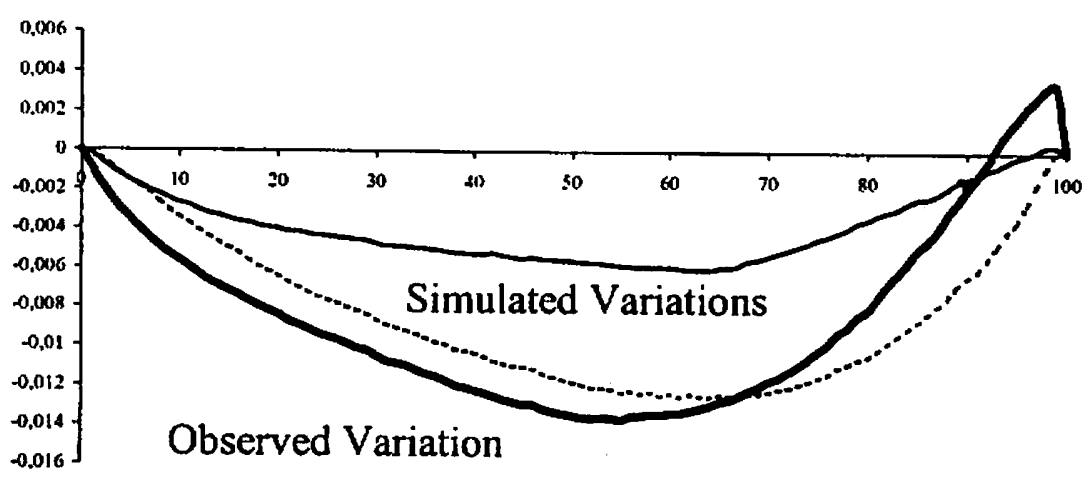

Figure 7 : Spouses

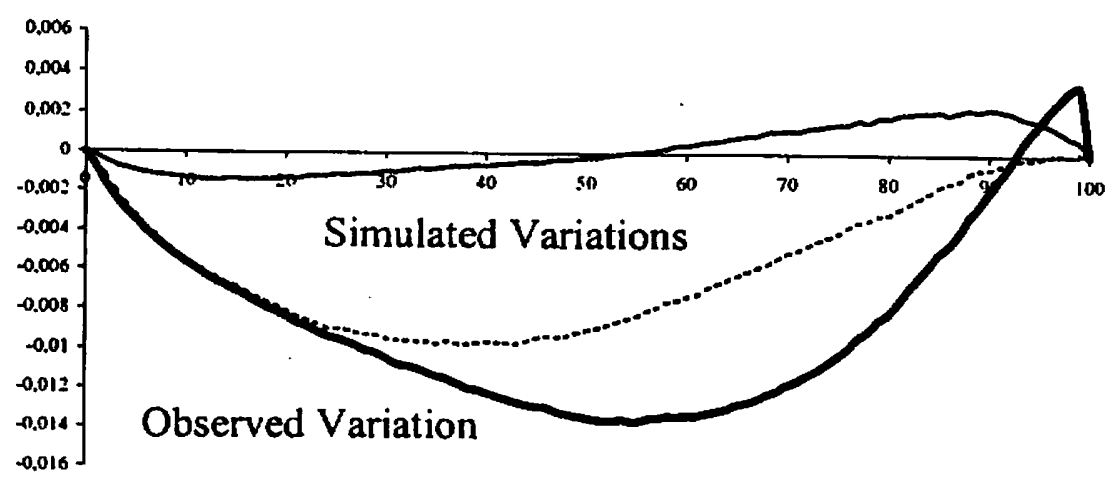

Figure 8 : Children 


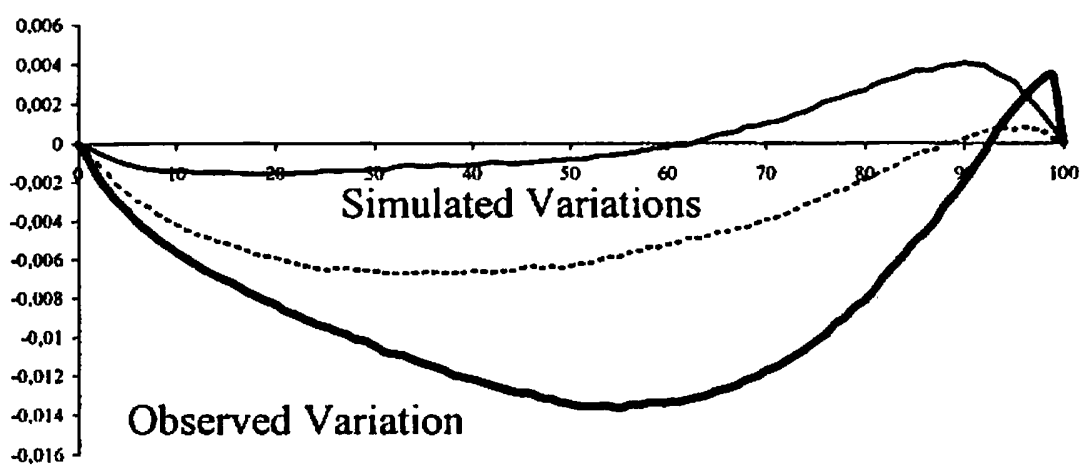

Figure 9 : Other members

Thick plain lines : observed variation.

Doted lines : simulations based on 1979 initial structure.

Light plain lines : simulations based on 1994 initial structure.

Notes: Abscises represent the cumulative share of households, ranked by increasing total income. The equivalence scale used is the square root of the total number of household members. The number of household members weights households.

lising effect induced both by entries into the labour force at the top of the distribution of household income and exits at the bottom. This evolution can be explained for one part by the rise in the participation of more educated women, who are strongly concentrated within richer households. For the other part, exits from the labour force of women belonging to poorer households can be explained as the result of a loosening of the budget constraint induced by the rapid rise in average income during the Taiwanese development process.

The specific impact of changes in the correlation between children income and total household income shown in figure 8 seems to go in the same direction even though the effect depends on the sensitivity properties of the inequality index when computations are made upon the 1979 reference year. The central mechanism, as before, concerns the lengthening of school enrolment, which had a stronger impact on children belonging to poorer households and which was allowed by the overall rise in income. Thus, it is clear that, all else being equal, the decrease in labour force participation has increased the correlation between household income and children income, since more children have no income in poorer households. Figure 8 isolates the effect, keeping marginal distributions (and thus participation in the labour market) unchanged, and shows, at least for simulations based on the 1994 data, a sizeable unequalizing effect.

Finally, figure 9 shows a very similar trend (although non-robust) concerning the other members of the household. This evolution should be linked to the lowering of the age of retirement over the period studied. Indeed, also as a result of rising overall income, older members of poorer 
households (parents or relatives) tend to have had more freedom in the choice of their desired retirement age. This of course implies a rise in the correlation between this income source and total household income.

\subsubsection{Summary of results}

The rank-decomposition method presented in this paper allows for a decomposition of the whole income distribution upon which standard inequality indexes can be straightforwardly computed. Between 1979 and 1994, the Gini coefficient for household primary income by adult equivalent rose from 0.271 to 0.288 . Table 5 summarizes this 0.017 point rise in terms of Gini coefficient using simulation results for the various effects presented figures 2 to 9 .

The three main results discussed above are clearly visible on this table $:$ i) changes in the marginal distribution of spouses' income have equalised, ii) changes in the marginal distribution of children's income increased overall inequality, and $i i$ ) changes in the correlation between the income of various household members were the strongest unequalizing force. This last result highlights the central role played on household income inequality by changes occurring within the structure of households and particularly in the assortative mating of spouses. Indeed, the magnitude of the effect measured for household heads and spouses is comparable to, or larger than the total observed change in inequality over the 1979-94 period.

One last comment concerns the path-dependency of the results. As mentioned before, simulated effects depend on the population structure that simulations are based upon. In particular, it appears that changes in correlations have a much stronger impact when evaluated on the 1979 population structure than on that of 1994 . This comes from the fact, already mentioned, that marginal distributions of income source became more equally distributed over the period studied, whereas correlation between sources increased. Indeed, the more unequally distributed income sources are, the higher the effect of a rise in the correlation between income sources is ${ }^{20}$.

20 As a polar case, the effect would be nuil if one of the two income sources were equally distributed. 
Table 5 : Summary of results using Gini coefficient (1979-94)

(\%)

\begin{tabular}{|c|c|c|}
\hline & \multicolumn{2}{|c|}{ Gini Coefficient } \\
\hline & 1979 Population* & 1994 Population ${ }^{*}$ \\
\hline Observed variation & \multicolumn{2}{|c|}{0.017} \\
\hline \multicolumn{3}{|c|}{ Variation due to marginal distributions } \\
\hline \multirow[t]{2}{*}{ Household head } & -0.001 & -0.002 \\
\hline & $(0.00046)^{* *}$ & $(0.00037)$ \\
\hline \multirow[t]{2}{*}{ Spouses } & -0.007 & -0.011 \\
\hline & $(0.00041)$ & $(0.00049)$ \\
\hline \multirow[t]{2}{*}{ Children } & 0.009 & 0.003 \\
\hline & $(0.00045)$ & $(0.00029)$ \\
\hline \multirow[t]{2}{*}{ Other members } & -0.002 & -0.003 \\
\hline & $\{0.00016)$ & $(0.00022)$ \\
\hline \multicolumn{3}{|c|}{ Variation due to correlation changes } \\
\hline \multirow[t]{2}{*}{ Household head } & 0.038 & 0.025 \\
\hline & $(0.0024)$ & $(0.0024)$ \\
\hline \multirow[t]{2}{*}{ Spouses } & 0.016 & 0.008 \\
\hline & $(0.0011)$ & $(0.0015)$ \\
\hline \multirow[t]{2}{*}{ Children } & 0.012 & 0.000 \\
\hline & $(0.0013)$ & $(0.0009)$ \\
\hline \multirow[t]{2}{*}{ Other members } & 0.008 & 0.000 \\
\hline & $(0.0015)$ & $(0.0014)$ \\
\hline
\end{tabular}

Note: $(*)$ Population upon which the simulation has been computed. The equivalence scale used is the square root of the total number of household members. The number of household members weights households.

A negative number indicates a decrease in inequality. Different signs in the two columns correspond to a non-robust effect (for the Gini coefficient).

(**) Standard errors within brackets are obtained by bootstrapping on 1000 replications. A bold figure indicates a significant number at the $95 \%$ level. 


\section{Conclusion}

This article shows that the decomposition procedure briefly initiated by Burtless (1999) can actually be systematized and provides a new general method for decomposing income inequality changes by factor components. The method, based on the concept of rank-correlation, provides a useful tool to counter some major drawbacks inherent to standard decomposition procedures.

Indeed, this method allows for a decomposition of the whole income distribution and is thus not restricted to the use of a specific inequality index. It provides a decomposition procedure for observed changes in Lorenz curves as well as any synthetic inequality measure and the results obtained depend on the specific sensitivity properties of chosen indexes at various points of the distribution, which is not the case for decomposition methods following Shorrocks' (1982) approach.

Moreover, the decomposition procedure proposed here provides useful answers to the central question raised by Shorrocks (1982) about the sharing of the role played by the correlation between sources among income sources. The rank-decomposition method indeed allows for a further decomposition step in distinguishing the specific impact of changes in the correlation between sources from that of changes in the marginal distribution of sources, whereas standard decomposition procedures only provide a global evaluation based on a given sharing rule for correlation factors, which, inevitably, is partial.

The implementation of the method to the Taiwan case illustrates the type of results it can provide and allows for a better understanding of some major factors behind the rise in household income inequality over the 197994 period. Indeed, three main sources of inequality change can be derived from this decomposition procedure $: i$ ) a sizeable equalizing effect coming from changes in the distribution of spouses' (marginal) income distribution, ii) a notable unequalizing effect induced by the decline in labour force participation of children following the rise in school enrolment, and iii) a major unequalizing effect (the magnitude of which is much stronger than that of the first two) coming from changes in the correlation between various household members' income. Finally, we argue here, that this last point should be linked with changes in the assortative mating of spouses and especially with rising endogamy in terms of education and age induced by profound sociological changes leading to a shift from traditional Chinese marriages to a freer choice of bride or groom.

Results for the Taiwanese case plead more generally in favour of the use and development of methods dealing with inequality decomposition by factor components. Indeed, the method proposed here is complementary to recent developments in inequality decomposition through micro-simulation techniques (Juhn, Murphy and Pierce (1993); Bourguignon and Martinez 
(1997); Bourguignon, Fournier and Gurgand (2001) $)^{21}$. These methods only provide a general evaluation of the impact of changes in population and household structure on income distribution and cannot isolate the specific factors highlighted here. Combining both approaches within a common framework would certainly be of great interest for the understanding of the major sources of inequality changes.

\section{Annex}

Tables 1 and 2 provide a recapitulation of simulations discussed section 2.2. For any individual (a) observed in $t$ :

- at ranks $n_{1}$ and $n_{2}$ with respect to $y_{1}$ and $y_{2}$,

- with observed income $y=y_{n 1}+y_{n 2}$,

the following individuals $(b)$ to $(d)$ can be defined as follows :

\begin{tabular}{|c|c|c|c|c|c|c|c|c|c|}
\hline \multirow{3}{*}{ Indiv. } & \multicolumn{4}{|c|}{ Date $t$} & \multicolumn{5}{|c|}{ Date t' } \\
\hline & Income & Rank & Incom & Rank & Indiv. & Income & Rank & Incon & Rank \\
\hline & $y_{1}$ & $r_{1}$ & $y_{2}$ & $r_{2}$ & & $y_{1}$ & $r_{1}$ & $y_{2}$ & $y_{2}$ \\
\hline$(a)$ & $y_{n 1}$ & $n_{1}$ & $y_{n 2}$ & $n_{2}$ & (c) & $n_{1}$ & $y_{n 1}^{\prime}$ & $l_{2}$ & $y_{l 2}$ \\
\hline (b) & $y_{m 1}$ & $m_{1}$ & $y_{m 2}$ & $m_{2}$ & $(d)$ & $m_{1}$ & $y_{m 1}^{\prime}$ & $n_{2}$ & $y_{n 2}^{\prime}$ \\
\hline $\begin{array}{c}\text { Mean } \\
\text { income }\end{array}$ & $\mu_{1}$ & & & & $\begin{array}{l}\text { Mean } \\
\text { income }\end{array}$ & & $\mu_{1}^{\prime}$ & & \\
\hline
\end{tabular}

Table 1 : Definitions

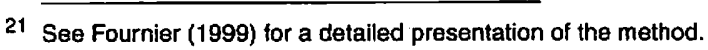


Martin Fournier

Following the notation described in table 1 , the two simulation procedures discussed in section 2.2 can be summarised as follows for any individual $(a)$ :

\begin{tabular}{l|cc}
\hline $\begin{array}{l}\text { Simulations for } \\
\text { individual (a) }\end{array}$ & $y_{1}$ & $y_{2}$ \\
\hline $\begin{array}{l}\text { Observed income } \\
\text { sources for individual } \\
\text { (a) at date } t\end{array}$ & $y_{n 1}$ & $y_{n 2}$ \\
\hline $\begin{array}{l}\text { Change in the } \\
\text { marginal distribution } \\
\text { of } y_{1} \text { keeping marginal } \\
\text { distribution of } y_{2} \text { and } \\
\text { correlation structure } \\
\text { unchanged (i) }\end{array}$ & $y_{n 1}=y_{n 1}^{\prime} \cdot \frac{\mu_{1}}{\mu_{1}^{\prime}}$ & $y_{n 2}$ \\
\hline $\begin{array}{l}y_{n 1}^{\prime} \text { is observed income for } \\
\text { Change in the } \\
\text { correlation structure } \\
\text { keeping marginal } \\
\text { distributions of } \\
\text { income sources } \\
\text { unchanged (iii) }\end{array}$ & \multicolumn{1}{|c}{$\tilde{y}_{n 1}=y_{m 1}$} & (observed) \\
& $\begin{array}{l}y_{m 1} \text { is observed income in } \\
\text { for individual }(b) \text { of rank } \\
m_{1} \text { in } y_{1}, m_{1} \text { being the } \\
\text { rank in } y_{1} \text { at date } t^{\prime} \text { for }\end{array}$ & (observed) \\
\hline
\end{tabular}

Table 2 : Rank-correlation method, recapitulation 


\section{Bibliography}

Atkinson A. B., (1997), "Bringing Income Distribution in from the Cold", Economic Journal, 107, pp. 297-321.

Atkinson A. B. and F. Bourguignon, (1998), "Introduction : Income Distribution and Economics", in A. B. Atkinson and F. Bourguignon (eds.); Handbook of Income Distribution, Vol. 1, North Holland.

Bourguignon F. and M. Martinez, (1997), Decomposition of the changes in the distribution of primary family income : a microsimulation approach applied to France, 1979-1989, Document de travail Delta, Paris.

Bourguignon F., M. Fournier and M. Gurgand, (2001), "Fast development with a Stable Income Distribution: Taiwan, 1979-94", Review of Income and Wealth, 47, No. 2, June, pp. 139-163.

Bourguignon F., M. Fournier and M. Gurgand, (1999), Female Labour Supply in the Course of Taiwan's Economic Development: 1979-94, Document de travail $\mathbf{n}^{\circ}$ 9920, CREST-INSEE, Paris.

Burtless G,. (1999), "Effects of growing wage disparities and changing family composition on the U.S. income distribution", European Economic Review, 43, pp. 853-65.

Chantreuil F. and A. Trannoy, (1997), Inequality Decomposition Values, Mimeo, THEMA, Université de Cergy-Pontoise.

Chantreuil F. and A. Trannoy, (1999), Inequality Decomposition Values: the Trade-off between Marginality and Consistency, Document de travail $\mathrm{n}^{\circ}$ 9924, THEMA, Université de Cergy-Pontoise.

Chu Y. P., (1997), Employment Expansion and Equitable Growth : Taiwan's Postwar Experience, Mimeo, Academia Sinica, Taipei.

Deaton A. and C. Paxson, (1993), Saving, growth and aging in Taiwan, NBER Working Paper No. 4330.

Di Nardo J., N. Fortin and T. Lemieux, (1996), "Labour market institutions and the distribution of wages 1973-1992: A semiparametric approach", Econometrica, 64, pp. 1001-1064.

Directorate general of budget, accounting and statistics (1996), Report on the Survey of Family Income and Expenditure in Taiwan Area of Republic of China, Executive Yuan, Republic of China.

Fei J., G. Ranis and S. Kuo, (1978), "Growth and the Family Distribution of Income by Factor Component", Quarterly Journal of Economics, February, pp. 17-54.

Fields G. S. and J. Leary, (1997), Economic and demographic aspects of Taiwan's rising family income inequality, Mimeo.

Fournier M., (1999), Développement et distribution des revenus : Analyses par décomposition de l'expérience taiwanaise, $\mathrm{PhD}$ dissertation, EHESS, Paris.

Gottschalk, R. and S. Danziger (1993), "Family structure, family size, and family income : accounting for changes in the economic well-being of children, 1968-1986", in S. Danziger and Gottschalk, R. (eds.), Uneven Tides : Rising Inequality in America, New York : Russel Sage foundation.

Hung R, (1996), "The Great U-Turn in Taiwan : Economic Restructuring and a Surge in Inequality", Journal of Contemporary Asia, 26, pp. 151-163. 
Juhn C., K. Murphy and B. Pierce, (1993), "Wage Inequality and the Rise in Returns to Skill", Journal of Political Economy, 101, pp. 410-442.

Kanbur R. and N. Lustig, (1999), Why is Inequality Back on the Agenda?, Paper prepared for the Annual Bank Conference on Development Economics, Washington, D.C., 28-30 April 1999.

Kuznets S., (1955), "Economics growth and income inequality", American Economic Review, 45, pp. 1-28.

Lerman R. I., (1996), "The Impact of the Changing US Family Structure on Child Poverty and Income Inequality", Economica, 63, pp. S119-S139.

Mc Nally D. and S. Mc Nally, (1995), A socio-linguistic approach of Matchmakers and Marriages, Mimeo, Sun Yat Sen University, Guangzhou.

Pyatt G., C. N. Chen and J. Fei, (1980), "The Distribution of Income by Factor Components", Quarterly Journal of Economics, 95, pp. 451-473.

Schultz T. P., (1997), Income Inequality in Taiwan 1976-1995: Changing Family Composition, Aging and Female Labour-Force Participation, Economic Growth Center Discussion Paper No.778, Yale University.

Shorrocks A. F., (1982), "Inequality Decomposition by Factor Components", Econometrica, 50 , pp. 193-211.

Shorrocks A. F., (1999), Decomposition procedures for distributional analysis : $A$ unified framework based on the Shapeley value, mimeo, University of Essex.

Tsai S. L., (1994), "Assortative Mating in Taiwan", in S. K. Lau, M. K. Lee, P. S. Wan and S. L. Wong (eds.), Inequalities and Development, Hong Kong Institute of Asia-Pacific Studies, The Chinese University of Hong Kong. 
